\title{
Mortality and Readmission After Cervical Fracture from a Fall in Older Adults: Comparison with Hip Fracture Using National Medicare Data
}

\author{
Zara Cooper, MD, MSc, ${ }^{a b c}$ Susan L. Mitchell, MD, MPH, ${ }^{\text {cde }}$ Stuart Lipsitz, ScD, ${ }^{\text {bf }}$ \\ Mitchel B. Harris, MD, ${ }^{g c}$ John Z. Ayanian, MD, MPP, ${ }^{\text {bi }}$ Rachelle E. Bernacki, MD, MS, ${ }^{f i}$ and \\ Ashish K. Jha, MD, MPH ${ }^{k}$
}

OBJECTIVES: To examine the prevalence of cervical spine fractures after falls in older Americans, to show changes in recent years, and to compare 12-month outcomes between individuals with cervical and hip fracture after falls.

DESIGN: Retrospective study of Medicare data from 2007 to 2011.

SETTING: Acute care hospitals.

PARTICIPANTS: Individuals aged 65 and older with cervical or hip fracture after a fall.

MEASUREMENTS: Cervical fracture rate, 12-month mortality, and readmission rate after injury.

RESULTS: Rates of cervical fracture increased from 4.6 per 10,000 in 2007 to 5.3 per 10,000 in 2011; rates of hip fracture decreased from 77.3 per 10,000 in 2007 to 63.5 per 10,000 in 2011. Participants with cervical fracture with and without spinal cord injury (SCI) were more likely than those with hip fracture to receive treatment at large hospitals $(59.4 \%$ and $54.1 \%$ vs $28.1 \%, P<.001)$, teaching hospitals $(49.3 \%$ and $40.0 \%$ vs $13.4 \%, P<.001)$, and regional trauma centers $(46.3 \%$ and $38.5 \%$ vs $13.0 \%$, $P<.001)$. Participants with cervical fracture without $(24.7 \%)$ and with SCI $(41.7 \%)$ had greater risk-adjusted mortality at 1 year than those with hip fracture $(22.7 \%)$ $(P<.001)$. By 1 year, $73.4 \%$ of participants with cervical fracture with and $59.5 \%$ without SCI and $59.3 \%$ of those

From the a Division of Trauma, Burns and Surgical Critical Care; ${ }^{b}$ Center for Surgery and Public Health, Brigham and Women's Hospital; ' Medical School of Medicine, Harvard University; ${ }^{\mathrm{d}}$ Department of Medicine, Beth Israel Deaconess Medical Center; ${ }^{\mathrm{C}}$ Institute for Aging Research, Hebrew SeniorLife; ${ }^{\mathrm{f}}$ Department of Psychosocial Oncology and Palliative Care, Dana-Farber Cancer Institute; ${ }^{\mathrm{g}}$ Department of Orthopedic Surgery, Brigham and Women's Hospital, Boston, Massachusetts; ${ }^{\mathrm{h}}$ Division of General Medicine; ${ }^{\mathrm{i}}$ Institute for Healthcare Policy and Innovation, University of Michigan, Ann Arbor, Michigan; 'Ariadne Labs; and ${ }^{\mathrm{k}} \mathrm{T} . \mathrm{H}$. Chan School of Public Health, Harvard University, Boston, Massachusetts.

Address correspondence to Dr. Zara Cooper, Department of Surgery, Brigham and Women's Hospital, 75 Francis St., Boston, MA 02115.

E-mail: zcooper@partners.org

DOI: $10.1111 /$ jgs. 13670 with hip fracture had died or were readmitted to the hospital $(P<.001)$.

CONCLUSION: Cervical spinal fractures occur in one of every 2,000 Medicare beneficiaries annually and appear to be increasing over time. Participants with cervical fracture had greater mortality than those with hip fracture. Given the increasing prevalence and the poor outcomes in this population, hospitals need to develop processes to improve care for these vulnerable individuals. J Am Geriatr Soc 63:2036-2042, 2015.

Key words: cervical fracture; mortality; readmission

$I^{n}$ the United States, older adults are more likely to be hospitalized for traumatic injury than younger individuals, ${ }^{1}$ with rates increasing $3 \%$ to $5 \%$ annually. ${ }^{2}$ People aged 65 and older now account for up to $25 \%$ of trauma admissions. ${ }^{3}$ Most trauma in older adults is related to falls, ${ }^{4}$ and the annual costs of acute care associated with falls in older adults is estimated to exceed $\$ 8.0$ billion. ${ }^{5}$ Severe trauma in older adults can have particularly devastating consequences, including long hospitalization and rehabilitation, permanent functional impairment, and death. Better understanding of the clinical consequences of trauma in older Americans and optimization of their treatment are essential to meeting the needs of this rapidly growing population.

Much of what is known about the trajectory of older adults after falls is from data on those with hip fracture. Hip fracture after a fall is associated with high morbidity and costs and has been a growing public health concern for decades, ${ }^{6,7}$ but cervical spinal fracture is another consequence of falls in older adults, and the types of individuals with this injury and their outcomes are largely unknown. Single-institution studies suggest that 1-year mortality associated with these injuries may be high, ${ }^{8}$ but there are 
no national data on the incidence of these injuries, the characteristics of the individuals experiencing cervical spinal fracture, types of hospitals where these individuals receive care, and how their short- and long-term outcomes compare with those of individuals with hip fracture.

Given the lack of national data on the frequency or outcomes of cervical fractures after falls, Medicare data were used to answer the following questions. How often do these injuries occur, and has the rate of injury changed over time? What are the characteristics of individuals with cervical spinal fractures, and how do they compare with individuals with hip fractures? What are the characteristics of the hospitals where these individuals receive care? How do rates of mortality and readmission during the first year after injury with cervical factures compare with those after hip fracture? What are the major causes for the first readmission to an acute hospital for individuals with cervical and hip fractures?

\section{METHODS}

\section{Data Sources}

The 100\% Medicare Provider Analysis and Review (MedPAR) file was used to identify inpatient care for beneficiaries enrolled in the fee-for-service program. The American Hospital Association (AHA) survey was used to identify hospital characteristics and the Medicare Impact File to obtain the hospital's Disproportionate Share Hospital index, which determines a hospital's eligibility to receive federal compensation for serving a disproportionate share of uninsured and Medicaid beneficiaries and is a proxy for caring for poor individuals. ${ }^{9}$ The Medicare Beneficiary Summary File was used to obtain vital status after discharge and insurance information.

\section{Study Sample}

Individuals discharged from acute care hospitals from January 1, 2007, through December 31, 2011, were included in the cohort. Data from 2012 were used to ensure 1 year of follow-up. Individuals younger than 65 and enrolled in a Medicare Advantage health plan for part of the year were excluded because they would not have had full claims data. First admission for cervical or hip fracture was considered the index case. Cervical fractures with and without spinal cord injury (SCI) were identified using International Classification of Diseases, Ninth Revision, Clinical Modification (ICD-9-CM) codes 805.0x, 805.1x, $806.0 x$, and $806.1 x$. The number of individuals who sustained high cervical fracture (atlanto-occipital, first or second cervical vertebrae (ICD-9 codes 805.00, 805.01, $805.11,805.02,805.12$ ) was also calculated. Hip fracture was identified using code 820.x, and low-impact falls were identified using codes 880.1, 884.2, 884.3, 884.4, 884.6, $885.9,888.0$, and 888.1. Individuals who fell from a height, including a ladder, were excluded (presuming that they would generally be more robust than individuals who suffered low-impact falls). Individuals who were discharged from federal hospitals or from hospitals outside of the 50 United States or the District of Columbia, or who were admitted to or discharged from non-acute care hospi- tals were also excluded. One thousand five hundred twenty-two $(0.14 \%)$ individuals who had both cervical spine and hip fracture were excluded. In cases in which a participant was transferred from one acute hospital to another, only data from the receiving hospital was used to determine readmission rate. Last, the reason for the first readmission to an acute care hospital was determined.

\section{Outcomes}

The primary outcome of interest was mortality 30, 90, and 360 days after admission. The secondary outcome was a composite measure of mortality and hospital readmission 30,90 , and 360 days after discharge from the index hospitalization.

\section{Other Variables}

Variables were examined to describe baseline characteristics of participants and the hospitals that treated them. Information on all participant characteristics was obtained from Medicare files and included demographic characteristics, comorbidities, and an injury severity measure. Demographic characteristics included age $(65-69,70-79, \geq 80)$, sex, and race (white, African American, other). Medical comorbidities, which were identified using ICD-9 codes in Medicare claims, included dementia, congestive heart failure, coronary artery disease, end-stage renal disease, and diabetes mellitus. The Hierarchical Condition Category (HCC) model, which the Centers for Medicare and Medicaid Services uses to adjust payment for individuals with chronic conditions, was used to adjust for participant comorbidities. ${ }^{10}$ The HCC includes 70 disease categories, which correlate to ICD-9 codes captured during all outpatient and inpatient encounters up to and including index admission and is superior to Charlson or Elixhauser measures for predicting mortality in Medicare beneficiaries. ${ }^{11}$ Dementia separately was controlled for because it is not included in the HCC. Head injury is a condition in the HCC and was therefore included in the adjusted model. Injury severity was quantified using ICD Programs for Injury Categorization ${ }^{12}$ conversion software to map each diagnosis code to an Abbreviated Injury Score and to calculate an Injury Seventy Score (ISS) $)^{13}(0-9$, low; 10-24, moderate; $\geq 25$, severe). Discharge location was also obtained from Medicare claims for beneficiaries with cervical fracture and hip fracture.

Information on hospital characteristics was obtained from the AHA database and included size (small, 1-99 beds; medium, 100-399 beds; large, $\geq 400$ beds), membership in the Council of Teaching Hospitals, trauma center status (regional, community, rural, nontrauma), region, profit status, and Disproportionate Share Hospital index (a proxy for caring for poor individuals).

\section{Analysis}

Participant and hospital characteristics were described using frequencies, percentages, means, and standard deviations where appropriate. Annual rates of cervical fracture and hip fracture were calculated per 10,000 Medicare beneficiaries for each of the study years (2007-2011) and dis- 
played graphically. Characteristics of older Medicare beneficiaries and discharge location of participants with cervical fracture and hip fracture were compared. Rao-Scott chi-square tests were used, which account for clustering at the hospital level.

Two outcomes were considered in these analyses: survival and composite measure of survival and hospital readmission. Survival was calculated from the date of index hospitalization and date of death, and readmission was calculated based on date of discharge from index hospitalization. Kaplan-Meier survival curves were used to examine unadjusted survival and composite rates of survival and readmission for individuals with cervical and hip fracture. Rao-Scott chi-square tests were used to compare unadjusted proportions of those who died by 30,90 , and 360 days after injury. ${ }^{14} \mathrm{~A}$ second analysis as performed to compare composite rates of death or readmission by 30 , 90 , or 360 days as a secondary outcome for participants with cervical fracture (with and without SCI) and hip fracture; since this outcome includes censored observations, these proportions were obtained from the unadjusted Kaplan-Meier survival curves and compared across three groups using a Wald test that takes clustering by hospital into account. ${ }^{14}$

To calculate adjusted proportions of death and composite death and readmission at the three time points (30, 90, 360 days) in the cervical and hip fracture groups, a weighted propensity score approach was used to calculate adjusted Kaplan-Meier curves. ${ }^{15,16} P$-values comparing the cervical and hip fracture groups were calculated accounting for clustering at the hospital level. ${ }^{14,16}$ The propensity for being in the cervical and hip fracture groups was calculated using logistic regression models with age, sex, race, ISS, HCC, dementia, and hospital characteristics as independent variables as predictors of each group. By estimating the propensity for being in each of the three groups (cervical fracture without SCI, cervical fracture with SCI, hip fracture) propensity score methods provide better control for observed confounding factors than regression models alone; propensity methods improve the ability to compare groups in observational studies. When the propensity-weighted Kaplan-Meier curves were calculated, each participant was weighted by the inverse propensity of being in their observed group, with the goal of balancing characteristics across the groups.

All analyses were conducted using SAS version 9.3 (SAS Institute, Inc., Cary, NC). $P<.05$ was considered statistically significant. The Partners human research committee and the institutional review board of the Harvard School of Public Health approved the study.

\section{RESULTS}

\section{Rates of Cervical Fracture and Hip Fracture over the Study Period}

For Medicare beneficiaries aged 65 and older in 2007 to 2011, there were 67,162 admissions for cervical fracture without SCI, 5,593 for cervical fracture with SCI, and $1,009,738$ admissions for hip fracture after a low-impact fall; $1,522(0.14 \%)$ individuals with both cervical and hip fracture were excluded from this analysis. Of participants with cervical fracture, $44.9 \%$ had high cervical injury (atlanto-occipital, first and second cervical vertebrate). The number of cervical fractures increased $15 \%$ from 4.6 per 10,000 Medicare beneficiaries in 2007 to 5.3 per 10,000 Medicare beneficiaries in 2011, whereas the number of hip fractures decreased $18 \%$ from 77.3 per 10,000 Medicare beneficiaries in 2007 to 63.5 per 10,000 Medicare beneficiaries in 2011 (Figure 1).

\section{Participant Characteristics}

Participants with cervical fracture were younger than those with hip fracture (aged $\geq 80: 60.8 \%$ without SCI, $46.4 \%$ with SCI, $70.0 \%$ hip) and more likely to be male $(42.8 \%$ without SCI, $61.7 \%$ with SCI, $27.1 \%$ hip). The majority of participants with cervical fracture without SCI (78.2\%) and hip fracture $(93.0 \%)$ had low-severity injuries (ISS $<9$ ). Participants with cervical fracture were more likely to have moderate $(19.6 \%$ without SCU, $52.3 \%$ with SCI, $6.5 \%$ hip, ISS $10-24)$ or severe injury $(2.2 \%$ without SCI, $17.0 \%$ with SCI, $0.4 \%$ hip, ISS $>25$ ) than participants with hip fracture. All differences in participant characteristics were statistically significant $(P<.001)$ (Table 1).

Participants with cervical fracture with or without SCI were more likely to die in the hospital than participants with hip fracture $(8.5 \%$ without SCI, $26.1 \%$ with SCI, $3.2 \%$ hip). Of participants discharged from the hospital, those with cervical facture were more likely to be discharged home $(30.1 \%$ without SCI, $12.0 \%$ with SCI, $8.7 \%$ hip). The majority of participants were discharged to a skilled nursing facility or long-term care $(54.9 \%$ without SCI, $52.7 \%$ with SCI, $83.6 \%$ hip). All differences in discharge location were statistically significant $(P<.001)$ (data not shown).

\section{Hospital Characteristics}

Participants with cervical fracture were more likely to receive care in large hospitals $(54.1 \%$ without SCI, $59.4 \%$ with SCI, $28.1 \%$ hip), teaching hospitals $(40.0 \%$ without SCI, $49.3 \%$ with SCI, $13.4 \%$ hip), and regional trauma centers (38.5\% without SCI, $46.3 \%$ with SCI, $13.3 \%$ hip).

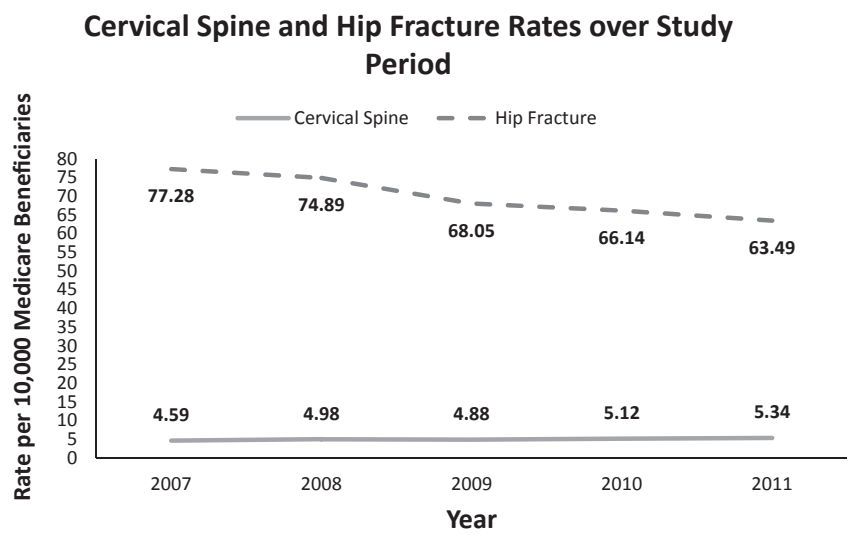

Figure 1. Rates of cervical spine and hip fractures in older Medicare beneficiaries after falls: 2007-2011. 
Table 1. Characteristics of Participants with Cervical Fracture and Hip Fracture

\begin{tabular}{|c|c|c|c|}
\hline \multirow[b]{2}{*}{ Characteristic } & $\begin{array}{c}\text { Cervical } \\
\text { Fracture } \\
\text { without Spinal } \\
\text { Cord Injury, } \\
\mathrm{n}=67,162\end{array}$ & $\begin{array}{c}\text { Cervical } \\
\text { Fracture with } \\
\text { Spinal Cord } \\
\text { Injury, } \\
n=5,693\end{array}$ & $\begin{array}{l}\text { Hip Fracture, } \\
n=1,009,738\end{array}$ \\
\hline & \multicolumn{3}{|c|}{$\%$} \\
\hline \multicolumn{4}{|l|}{ Age } \\
\hline $65-69$ & 10.4 & 17.0 & 5.8 \\
\hline $70-79$ & 28.8 & 36.6 & 24.2 \\
\hline$\geq 80$ & 60.8 & 46.4 & 70.0 \\
\hline \multicolumn{4}{|l|}{ Race } \\
\hline White & 92.8 & 87.7 & 93.2 \\
\hline Black & 3.9 & 7.9 & 3.5 \\
\hline Other & 3.3 & 4.4 & 3.4 \\
\hline \multicolumn{4}{|l|}{ Sex } \\
\hline Male & 42.8 & 61.7 & 27.1 \\
\hline Female & 57.2 & 38.3 & 72.9 \\
\hline \multicolumn{4}{|l|}{ Comorbidities } \\
\hline Dementia & 1.4 & 0.8 & 2.3 \\
\hline $\begin{array}{l}\text { Congestive } \\
\text { heart failure }\end{array}$ & 18.4 & 14.4 & 19.8 \\
\hline $\begin{array}{l}\text { Coronary } \\
\text { artery disease }\end{array}$ & 12.0 & 11.4 & 11.4 \\
\hline Renal failure & 17.1 & 16.3 & 17.7 \\
\hline $\begin{array}{l}\text { Diabetes } \\
\text { mellitus }\end{array}$ & 16.4 & 16.1 & 15.7 \\
\hline $\begin{array}{l}\text { Chronic } \\
\text { obstructive } \\
\text { pulmonary } \\
\text { disease }\end{array}$ & 13.3 & 10.8 & 16.5 \\
\hline \multicolumn{4}{|c|}{ Injury severity score } \\
\hline 0-9 (low) & 78.2 & 30.6 & 93.0 \\
\hline $\begin{array}{l}10-24 \\
\text { (moderate) }\end{array}$ & 19.6 & 52.3 & 6.5 \\
\hline$\geq 25$ (severe) & 2.2 & 17.0 & 0.4 \\
\hline
\end{tabular}

All differences were statistically significant across groups $(P<.001)$.

Hospital characteristics and the distribution of these three groups of participants are presented in Table 2 .

\section{Survival}

Unadjusted mortality over 1 year of participants with cervical fracture without SCI, cervical fracture with SCI, and hip fracture was compared (Figure 2). In adjusted analyses accounting for participant factors and hospital characteristics, participants with cervical fractures without and with SCI had substantially higher 30-day mortality than those with hip fracture $(13.0 \%$ without SCI, $28.4 \%$ with SCI, $8.1 \%$ hip respectively, $P<.001)$. This gap persisted at 90 days $(18.5 \%$ without SCI, $35.6 \%$ with SCI, $14.7 \%$ hip, $P<.001)$ and 1 year after the initial hospitalization $(24.5 \%$ without SCI, $41.7 \%$ with SCI, $22.7 \%$ hip, $P<.001)$ (Table 3).

\section{Survival and Readmission}

Adjusted rates of composite mortality and readmissions were high in both groups; by 30 days, approximately one-
Table 2. Characteristics of Hospitals Where Individuals with Cervical Fracture and Hip Fracture Receive Care

\begin{tabular}{|c|c|c|c|}
\hline \multirow[b]{2}{*}{ Characteristic } & $\begin{array}{c}\text { Cervical } \\
\text { Fracture } \\
\text { without } \\
\text { Spinal Cord } \\
\text { Injury, } \\
\text { n }=67,162\end{array}$ & $\begin{array}{c}\text { Cervical } \\
\text { Fracture } \\
\text { with Spinal } \\
\text { Cord Injury, } \\
n=5,693\end{array}$ & $\begin{array}{l}\text { Hip Fracture, } \\
n=1,009,738\end{array}$ \\
\hline & \multicolumn{3}{|c|}{$\%$} \\
\hline \multicolumn{4}{|c|}{ Hospital size (beds, n) } \\
\hline Small $(<100)$ & 3.4 & 1.9 & 12.0 \\
\hline $\begin{array}{l}\text { Medium (100- } \\
399)\end{array}$ & 42.5 & 38.7 & 59.9 \\
\hline Large $(\geq 400)$ & 54.1 & 59.4 & 28.1 \\
\hline $\begin{array}{l}\text { Major teaching } \\
\text { hospital }\end{array}$ & 40.0 & 49.3 & 13.4 \\
\hline \multicolumn{4}{|l|}{ Trauma center level } \\
\hline Regional & 38.5 & 46.3 & 13.3 \\
\hline Community & 33.0 & 30.0 & 34.6 \\
\hline Rural and other & 28.5 & 23.7 & 52.1 \\
\hline \multicolumn{4}{|l|}{ Region } \\
\hline Northeast & 20.3 & 22.9 & 18.7 \\
\hline Midwest & 26.4 & 22.9 & 24.7 \\
\hline South & 37.7 & 36.9 & 41.2 \\
\hline West & 15.6 & 17.4 & 15.4 \\
\hline \multicolumn{4}{|l|}{ Profit status } \\
\hline For profit & 9.1 & 8.6 & 13.1 \\
\hline Not for profit & 76.4 & 73.8 & 75.0 \\
\hline Public & 14.5 & 17.7 & 11.9 \\
\hline $\begin{array}{l}\text { Disproportionate } \\
\text { Share Hospital }\end{array}$ & 13.2 & 16.5 & 8.1 \\
\hline
\end{tabular}

All differences were statistically significant across groups $(P<.001)$.

${ }^{a}$ Top decile in Disproportionate Share Hospitals index.

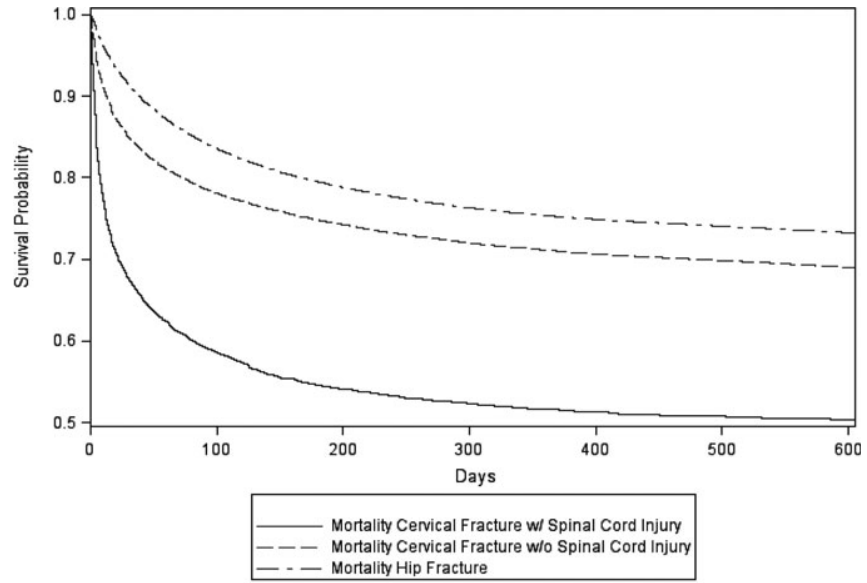

Figure 2. Mortality of elderly Medicare beneficiaries with cervical and hip fracture after fall.

third of participants had died or been readmitted $(31.6 \%$ without SCI, $50.1 \%$ with SCI, $29.7 \%$ hip, $P<.001)$; at 360 days, more than half had been readmitted $(59.5 \%$ without SCI, $73.4 \%$ with SCI, $59.3 \%$ hip, $P<.001$ across three groups, $P=.50$ without SCI vs hip) (Table 3 ). The top five reasons for the first readmission within 1 year of 
Table 3. Adjusted Mortality and Composite Mortality and Readmissions After Cervical and Hip Fracture

\begin{tabular}{|c|c|c|c|c|}
\hline & $\begin{array}{c}\text { Cervical } \\
\text { Fracture } \\
\text { without } \\
\text { Spinal Cord } \\
\text { Injury, } \\
\text { n }=67,162\end{array}$ & $\begin{array}{c}\text { Cervical } \\
\text { Fracture } \\
\text { with Spinal } \\
\text { Cord } \\
\text { Injury, } \\
\text { n }=5,693\end{array}$ & $\begin{array}{c}\text { Hip } \\
\text { Fracture, } \\
\mathbf{n}=1,009,738\end{array}$ & $P$-Value \\
\hline Outcome & \multicolumn{4}{|c|}{$\%$} \\
\hline \multicolumn{5}{|l|}{ Mortality } \\
\hline 30-day & 13.0 & 28.4 & 8.1 & $<.001$ \\
\hline 90-day & 18.5 & 35.6 & 14.7 & $<.001$ \\
\hline 360-day & 24.5 & 41.7 & 22.7 & $<.001$ \\
\hline \multicolumn{5}{|c|}{ Composite mortality and readmission } \\
\hline 30-day & 31.6 & 50.1 & 29.7 & $<.001$ \\
\hline 90-day & 43.3 & 62.8 & 42.1 & $<.001$ \\
\hline 360-day & 59.5 & 73.4 & 59.3 & $<.001$ \\
\hline
\end{tabular}

the incident admission to an acute care hospital for all three groups were rehabilitation, pneumonia, septicemia, urinary tract infection, and hip fracture (Appendix 1).

\section{DISCUSSION}

Approximately five per 10,000 Medicare beneficiaries had a cervical spinal fracture per year from 2007 through 2011, and the rates are increasing. Important clinical differences between individuals with cervical fracture and hip fracture included age, sex, and ISS. Men are more likely to sustain cervical spine trauma, and women are more likely to sustain hip fracture. ${ }^{17}$ One possible explanation is that, because hip fracture is so much more common than cervical fracture after low-impact falls, fall prevention and treatment for osteoporosis may shift the age-specific incidence of hip fracture toward the oldest adults, who are more likely to be women. ${ }^{18}$ Not surprisingly, head injury is closely associated with cervical spinal injury, ${ }^{19}$ leading to higher ISS in individuals with cervical fracture with and without SCI. After accounting for these differences between groups using propensity score modeling, it was found that, despite being younger, having fewer comorbid illnesses, and being more likely to receive care at teaching hospitals and higher-level trauma hospitals, Medicare beneficiaries who sustained a cervical fracture after a low-impact fall were nearly twice as likely to die within 30 days of their injury as those who sustained a hip fracture. Furthermore, within 1 year of injury, almost one-quarter of participants with a cervical fracture without SCI had died, and more than half had died or been readmitted. Of those with cervical fracture with SCI, at 1 year, more than $40 \%$ had died and almost three-quarters had died or been readmitted. Given the high mortality and suffering that this condition cause, it is surprising that little attention has been paid to determining its epidemiology or identifying its consequences.

The current study corroborates single-center studies demonstrating high mortality in older adults with cervical fracture and extends this work by using a national sample to demonstrate that cervical fracture is occurring with increasing frequency and has health outcomes that are worse than for hip fracture. ${ }^{7}$ The Centers for Disease Control and Prevention guidelines suggest that older injured adults should receive treatment at trauma centers, because even when they are less severely injured, they are less likely to display physiological signs that would activate transfer in younger individuals, ${ }^{20}$ but participants with cervical fractures were much more likely to receive care at large teaching hospitals and regional or community trauma centers. Although directing care to these institutions may be necessary to optimize resources for the mostvulnerable individuals, it may be insufficient to improve outcomes.

Older adults with cervical fracture could have such poor outcomes from underlying conditions or because of adverse consequences from the injury or how it is managed. For example, individuals with cervical fracture who are treated with halo fixation have high rates of dysphagia and aspiration. ${ }^{21}$ Highly coordinated, multidisciplinary care for older injured adults, including medical management by a hospitalist, is associated with lower complication rate, shorter hospital length of stay, and less likelihood of discharge to a long-term care facility. ${ }^{22,23}$ Trauma centers that treat higher volumes of older adults have lower of in-hospital mortality, complication rates, and failure-to-rescue rates than centers with lower volumes of older adults. ${ }^{24}$ Developing new and better treatment strategies for this population would also be immensely helpful. For example, improving outcomes in older adults who sustain fractures after falls warrants greater focus on medical processes of care and may require specialized pathways, such as Acute Care of the Elderly Units. ${ }^{25}$ Furthermore, clinicians and policy-makers must continue to focus on reducing fractures in elderly adults by increasing knowledge of risk factors for falls and developing individualized fall-prevention programs. ${ }^{26}$ This is particularly important because, in this study, hip fracture was the fifth leading cause of readmission in participants with cervical fracture and in those with hip fracture.

Composite rates of mortality and readmission for participants with cervical fracture rivaled or, in the case of SCI, exceeded rates for those with hip fracture. Readmissions are important for two reasons. First, transitions of care and hospital readmissions reduce quality of life and are associated with greater functional dependence and mortality, especially after surgery. ${ }^{27}$ In individuals with limited life expectancy because of advanced dementia or other underlying illness, or in whom acceptable functional recovery is unlikely, clear discussions about goals of care should precede hospital discharge. In these cases, offering palliative care, supporting caregivers, and easing transitions to comfort-directed care may be most appropriate. Given their high rates of readmission, older adults who have experienced a trauma with a cervical fracture are an appropriate target for interventions to improve transitions of care and reduce hospital readmission.

This study has several limitations. First, MedPAR is a large administrative database lacking the detailed clinical data needed for optimal risk adjustment. It does not include physiological prehospital data, obscuring other factors that could contribute to high mortality after injury. Furthermore, ICD-9 codes do not specify the anatomical 
characteristics of a fracture that may make it unstable and therefore more severe. Although the study design sought to control for injury characteristics by using propensity score modeling and adjusting for injury severity, whether individuals were triaged correctly and that individuals received care at the appropriate site of care could not be determined. Second, individuals with cervical fracture may have greater mortality than other injured individuals because they are sicker in ways that could not be measured. For example, frailty or diminished functional reserve is strongly associated with falls ${ }^{28}$ but is not captured in billing codes, which is why the outcomes of individuals with cervical fracture were compared with outcomes of those with hip fracture, which also occur in older adults who are often frail. Third, there is a lack of standardized approaches to cervical fractures in elderly adults, and it is unclear which individuals benefit most from surgery vs spinal immobilization alone. It was not possible to determine the appropriateness of surgery or its effect on outcomes after cervical fracture, because detailed information about the injury itself was not available.

Elderly adults who sustain cervical fractures after lowimpact falls have high mortality and hospital readmission rates for up to 1 year. Much of that risk of death is in the early weeks after trauma, but the risk of poor outcomes remains high, even higher than with hip fracture. Hospitals and healthcare systems need to determine optimal strategies for these individuals given the high risk of death and healthcare use during the year after injury. Identifying older adults who are most susceptible to cervical fracture and using preventive measures before falls and more-effective clinical and rehabilitative management strategies during and after hospitalization will be critical to ensuring that this vulnerable population of older Americans receives the most-appropriate treatment to achieve the best possible outcomes.

\section{ACKNOWLEDGMENTS}

We thank Jie Zheng, PhD, for her help with programming support and Dianali Rivera Morales, MS, Daniel Liebman, BA, and Garret Johnson, BS, for their assistance with manuscript preparation and submission.

This study was funded in part by the American Geriatrics Society Jahnigen Career Development Award (Cooper), National Institute on Aging GEMSSTAR 1R03AG042361-01 (Cooper), and K24AG033640 (Mitchell).

\section{Conflict of Interest: None.}

Author Contributions: Drs. Cooper and Jha had full access to all data in the study and take responsibility for the integrity of the data and the accuracy of the analysis. Study concept and design: Cooper, Jha, Mitchell, Lipsitz, Ayanian, Harris, Bernacki. Data acquisition: Jha. Data analysis and interpretation: Cooper, Mitchell, Lipsitz, Ayanian, Harris, Bernacki, Jha. Drafting of manuscript: Cooper, Jha. Critical revision of manuscript for important intellectual content: Cooper, Mitchell, Lipsitz, Jha, Ayanian, Harris, Bernacki. Statistical analysis: Cooper, Lipsitz, Jha. Obtained funding: Cooper, Mitchell, Jha. Administrative, technical, or material support: Cooper, Jha. Study supervision: Jha.
Sponsor's Role: The sponsors played no role in the design or conduct of the study; data collection, management, analysis, or interpretation; preparation, review, or approval of the manuscript; or decision to submit the manuscript for publication.

\section{REFERENCES}

1. Ciesla DJ, Pracht EE, Tepas JJ III et al. The injured elderly: A rising tide. Surgery 2013;154:291-298.

2. Nirula R, Gentilello LM. Futility of resuscitation criteria for the "young" old and the "old" old trauma patient: A national trauma data bank analysis. J Trauma 2004;57:37-41.

3. Haas B, Gomez D, Xiong W et al. External benchmarking of trauma center performance: Have we forgotten our elders? Ann Surg 2011;253:144150.

4. Centers for Disease Control and Prevention. Web-based Injury Statistics Query and reporting System (WISQARS), 2010 [on-line]. Available at http://www.cdc.gov/injury/wisqars/index.html Accessed November 30, 2010.

5. Roudsari BS, Ebel BE, Corso PS et al. The acute medical care costs of fallrelated injuries among the U.S. older adults. Injury 2005;36:1316-1322.

6. Magaziner J, Lydick E, Hawkes W et al. Excess mortality attributable to hip fracture in white women aged 70 years and older. Am J Public Health 1997;87:1630-1636.

7. Bentler SE, Liu L, Obrizan M et al. The aftermath of hip fracture: Discharge placement, functional status change, and mortality. Am J Epidemiol 2009;170:1290-1299.

8. Harris MB, Reichmann WM, Bono CM et al. Mortality in elderly patients after cervical spine fractures. J Bone Joint Surg Am 2010;92:567-574.

9. Centers for Medicare and Medicaid Services. Disproportionate Share Hospital (DSH): The Medicare DSH adjustment (42 CFR 412.106), 2012 [on-line]. Available at https://www.cms.gov/Medicare/Medicare-Fee-for-Service-Payment/AcuteInpatientPPS/dsh.html Accessed June 21, 2012.

10. Pope GC, Kautter J, Ellis RP et al. Risk adjustment of Medicare capitation payments using the CMS-HCC model. Health Care Financ Rev 2004;25:119-141.

11. Li P, Kim MM, Doshi JA. Comparison of the performance of the CMS Hierarchical Condition Category (CMS-HCC) risk adjuster with the Charlson and Elixhauser comorbidity measures in predicting mortality. BMC Health Serv Res 2010;10:245.

12. Sears JM, Blanar L, Bowman SM. Predicting work-related disability and medical cost outcomes: A comparison of injury severity scoring methods. Injury 2014;45:16-22.

13. Baker SP, O’Neill B, Haddon W Jr et al. The Injury Severity Score: A method for describing patients with multiple injuries and evaluating emergency care. J Trauma 1974;14:187-196.

14. Wei L-J, Lin DY, Weissfeld L. Regression analysis of multivariate incomplete failure time data by modeling marginal distributions. J Am Stat Assoc 1989;84:1065-1073.

15. Xie J, Liu C. Adjusted Kaplan-Meier estimator and log-rank test with inverse probability of treatment weighting for survival data. Stat Med 2005;24:3089-3110.

16. Nguyen LL, Hevelone N, Rogers SO et al. Disparity in outcomes of surgical revascularization for limb salvage: Race and gender are synergistic determinants of vein graft failure and limb loss. Circulation 2009;119:123130.

17. Amin S, Achenbach SJ, Atkinson EJ et al. Trends in fracture incidence: A population-based study over 20 years. J Bone Miner Res 2014;29:581-589.

18. Bergstrom U, Jonsson H, Gustafson Y et al. The hip fracture incidence curve is shifting to the right. Acta Orthop 2009;80:520-524.

19. Wang H, Coppola M, Robinson RD et al. Geriatric trauma patients with cervical spine fractures due to ground level fall: Five years experience in a level one trauma center. J Clin Med Res 2013;5:75-83.

20. Sasser SM, Hunt RC, Faul M et al. Guidelines for field triage of injured patients. Recommendations of the National Expert Panel on Field Triage, 2011. MMWR Recomm Rep 2012;61:1-20.

21. Bradley JF III, Jones MA, Farmer EA et al. Swallowing dysfunction in trauma patients with cervical spine fractures treated with halo-vest fixation. J Trauma 2001;70:46-48; discussion 48-50.

22. Mangram AJ, Mitchell CD, Shifflette VK et al. Geriatric trauma service: A one-year experience. J Trauma Acute Care Surg 2012;72:119-122.

23. Lenartowicz M, Parkovnick M, McFarlan A et al. An evaluation of a proactive geriatric trauma consultation service. Ann Surg 2012;256:10981101. 
24. Matsushima K, Schaefer EW, Won EJ et al. Positive and negative volumeoutcome relationships in the geriatric trauma population. JAMA Surg 2014;149:319-326.

25. Baztan JJ. Improving hospital hospitality in elderly patients with acute disease. Rev Esp Geriatr Gerontol 2008;43:129-130.

26. Karlsson MK, Vonschewelov T, Karlsson C et al. Prevention of falls in the elderly: A review. Scand J Public Health 2013;41:442-454.
27. Covinsky KE, Palmer RM, Fortinsky RH et al. Loss of independence in activities of daily living in older adults hospitalized with medical illnesses: Increased vulnerability with age. J Am Geriatr Soc 2003;51:451-458.

28. Ensrud KE, Ewing SK, Cawthon PM et al. A comparison of frailty indexes for the prediction of falls, disability, fractures, and mortality in older men. J Am Geriatr Soc 2009;57:492-498.

\section{APPENDIX 1:}

Top Five Reasons for First Readmission of Medicare Beneficiaries to Acute Care Hospital After Cervical Fracture and Hip Fracture: 2007-2011

\section{Primary Diagnosis (International Classification of Diseases, Ninth Revision, Code)}

Cervical Fracture without Spinal Cord Injury, $n=\mathbf{2 8 , 7 8 6}$
Cervical Fracture with Spinal Cord Injury, $n=2,202$
Hip Fracture,

$\mathrm{n}=\mathbf{4 8 2 , 1 0 2}$

\begin{tabular}{lr}
\hline Rehabilitation (V5789) & 11.7 \\
Pneumonia (486.XX) & 5.1 \\
Septicemia (038.9) & 3.7 \\
Urinary tract infection (599.0) & 3.6 \\
Hip fracture (820.21) & 1.3
\end{tabular}

11.7
5.1
3.7
3.6
1.3

$\begin{array}{ll}5.1 & 3.3 \\ 3.7 & 5.9\end{array}$

$\begin{array}{ll}5.1 & 5.9\end{array}$

$=3.0$

$\begin{array}{ll}3.3 & 0.5\end{array}$

